\title{
Benefits of Exercise Training in the Treatment of Heart Failure. Study with a Control Group
}

\author{
Mário Sérgio Vaz da Silva, Edimar Alcides Bocchi, Guilherme Veiga Guimarães, Carlos Roberto Padovani, \\ Maria Helena Gaíva G. da Silva, Shirley Ferreira Pereira, Ronaldo Ducchesi Fontes \\ Cuiabá, MT - São Paulo, SP - Brazil
}

\begin{abstract}
Objective - Exercise training programs have been proposed as adjuncts to treatment of heart failure. The effects of a 3-month-exercise-training-program with 3 exercise sessions per week were assessed in patients with stable systolic chronic heart failure.
\end{abstract}

Methods - We studied 24 patients with final left ventricle diastolic diameter of $70 \pm 10 \mathrm{~mm}$ and left ventricular ejection fraction of $37 \pm 4 \%$. Mean age was $52 \pm 16$ years. Twelve patients were assigned to an exercise training group (G1), and 12 patients were assigned to a control group (G2). Patients underwent treadmill testing, before and after exercise training, to assess distance walked, heart rate, systolic blood pressure, and double product.

Results - In G2 group, before and after 3 months, we observed, respectively distance walked, $623 \pm 553$ and $561 \pm 460 \mathrm{~m}$ (ns); peak heart rate, $142 \pm 23$ and $146 \pm 33 \mathrm{~b} /$ min (ns); systolic blood pressure, $154 \pm 36$ and $164 \pm 26$ $\mathrm{mmHg}(\mathrm{ns})$; and double product, $22211 \pm 6454$ and $24293 \pm 7373$ (ns). In G1 group, before and after exercise, we observed: distance walked, $615 \pm 394$ and $970 \pm 537 \mathrm{~m}$ $(p<0.003)$ peak heart rate, $143 \pm 24$ and $143 \pm 29 \mathrm{~b} / \mathrm{min}$ (ns); systolic blood pressure, $136 \pm 33$ and $133 \pm 24 \mathrm{mmHg}$

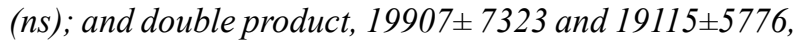
respectively. Comparing the groups, a significant difference existed regarding the variation in the double product, and in distance walked.

Conclusion - Exercise training programs in patients with heart failure can bring about an improvement in physical capacity.

Keywords: exercise training, exercise, heart failure

Instituto de Saúde Coletiva da Universidade Federal de Mato Grosso e Instituto do Coração do Hospital das Clínicas da FMUSP

Mailing address: Edimar Alcides Bocchi - Rua Oscar Freire, 2077/161 - 05409-011

São Paulo, SP - E-mail: dcledimar@incor.usp.br
Heart failure is currently an important public health problem. One percent of the population is estimated to have it and $1 / 5$ die every year, at the ratio of 3/1,000 inhabitants/ year. In the United States, heart failure occurs in about 2.2 million people, and contributes to over 500 thousand s hospitalizations and, approximately, 250 thousand deaths every year ${ }^{1,2}$. In the State of Mato Grosso, these values represent an average of 9,000 hospitalizations and 350 deaths annually, according to Sistema Único de Saúde (Single Health System) (Secretaria Estadual de Saúde do Mato Grosso) (State Health Ministry).

Despite the progress in the treatment of heart failure, high mortality and morbidity still occur ${ }^{3}$. Exercise training programs are among the recommended procedures to reduce morbidity and, in some situations, mortality ${ }^{4-6}$. Generally, procedures, which are not always available, and are expensive and complex are used for individual assessment of the benefits of the programs, such as ergospirometry, among others. This has limited their broad use in the community. On the other hand, in our community, no investigations have been performed and published about the beneficial role of exercise training programs in patients with heart failure apart from isolated cases, without a control group. Cultural factors and patients'own characteristics, such as age, ethnicity, etc., could influence possible beneficial results.

The objective of this investigation was to study the effect of exercise on the physical capacity of patients with heart failure, using a program of easy application and low cost in the community instead of complex investigations.

\section{Methods}

The investigation was performed from October 1997 to March 1999, at the ambulatory cardiology unit of the Hospital Universitário Júlio Müller (HUJM), at the Universidade Federal de Mato Grosso (Federal University of Mato Grosso), and at the Instituto de Cardiologia do Mato Grosso (Institute of Cardiology of Mato Grosso). Patients were referred primarily from 3 screening services, the University 
Hospital Júlio Müller, Cardiology Institute of Mato Grosso, and Posto de Saúde do Bairro Osmar Cabral (Public health service of Osmar Cabral Court).

All patients who were sent to the cardiology ambulatory unit had on echocardiography final left ventricle diastolic diameter $\geq 60 \mathrm{~mm}$ and ejection fraction $\leq 45 \%$, with signs and symptoms of heart failure. They were invited to take part in the study by the cardiologist as long as they did not have any of the exclusion criteria, which were clinical instability in the last 3 months, uncontrolled atrial or ventricular arrhythmia, myocardial infarction in the last 3 months, angina or any other manifestation of ischemia, hypertrophic myocardiopathy, restrictive myocardiopathy, cardiopathy that required surgical correction, pulmonary disease, primary valvulopathy, associated disease involving the ability to exercise, blood hypertension, and difficulty in complying with the protocol. Of the 35 patients selected, 24 (18 men and 6 women) agreed to take part in the research and were sent to the Cardiology Institute of Mato Grosso to undergo investigation for diagnosis, improvement of the available therapeutics, and treadmill testing. Afterwards, they were sent to the physical trainer to develop the study. Patients' characteristics are found in table I. All patients gave their written consent to take part in the study, approved by the ethics committee of the Federal University of Mato Grosso. Medication remained unchanged during the application of the exercise program in both groups.

The 24 patients in the study were randomly assigned to 2 different groups: group 1 was formed by 12 patients undergoing the exercise-training program, and group 2 was formed by 12 patients who were not undergoing the exercise-training program. Both groups were followed equally by the same treatment team, except regarding the training. Selection of groups was performed using systematic probability sampling 7 . Groups were comparable in their characteristics (tab. I). We determined in both groups at the beginning of the investigation and at the end of the training period maximum distance walked on the treadmill (in meters), heart rate (in b/min) at rest and at peak exercise, systolic blood pressure at rest and at peak exercise (in $\mathrm{mmHg}$ ), and calculation of double product (systolic blood pressure $\mathrm{x}$ heart rate).

The treadmill protocol used to assess patients was the modified Naugthon ${ }^{8}$. We used the electric treadmill Ecafix, model EG 700X, for the treadmill test, connected to an Acer Mate computer, with the program Ecafix cardio perfect (Ecafix 3-4 ST), model number A25374, with continuous monitoring of heart rate and of an electrocardiogram. Blood pressure was assessed with the auscultatory method with a mercury column sphygmomanometer. After 2 minutes in the upright position without exercise, patients were encouraged to perform exercises until symptoms (fatigue or dyspnea) made them unable to continue the test.

The exercise training program of patients lasted 3 months, at 3 times a week. Each session lasted 30 to 60 minutes $^{9-11}$. Exercises were performed at the Hospital Santa Cruz during the morning.

Based on the results obtained on the initial treadmill

\begin{tabular}{|c|c|c|}
\hline \multicolumn{3}{|c|}{$\begin{array}{l}\text { Table I - Characteristics of the patients who did and did not } \\
\text { participate in the exercise-training program in the beginning of } \\
\text { the investigation }\end{array}$} \\
\hline Variable & Exercise training & Control group \\
\hline Age (years) & $48 \pm 14$ & $56 \pm 16$ \\
\hline Gender (M/F) & $9 / 3$ & $9 / 3$ \\
\hline Functional Class-pts & I- 4. II- 4. III- 4 & I- 3. II- 6 . III- 3 \\
\hline \multicolumn{3}{|l|}{ Medication (\%) } \\
\hline Diuretics & 75 & 67 \\
\hline ACE inhibitor & 67 & 67 \\
\hline Digitalis & 83 & 75 \\
\hline Antiarrhythmic drugs & 8 & 17 \\
\hline Potassium chloride & 33 & 42 \\
\hline \multicolumn{3}{|l|}{ Etiology $(\%)$} \\
\hline Ischemic & 33.3 & 16.7 \\
\hline Enlarged idiopathic & 16.7 & 16.7 \\
\hline Hypertensive & 16.7 & 41.7 \\
\hline Chagasic & 25 & 16.7 \\
\hline Valvular & 8.3 & 8.3 \\
\hline FLVDD (mm) (mean) & 70 & 68 \\
\hline Distance $(\mathrm{m})$ & 615.3 & 623.9 \\
\hline $\mathrm{SBP}$ at rest (mmhg) & 107.9 & 121.7 \\
\hline Double product & 19906.7 & 22045.8 \\
\hline HR at rest (b/min) & 82.2 & 81.2 \\
\hline $\operatorname{LVEF}(\%)$ & 38.1 & 37.3 \\
\hline \multicolumn{3}{|c|}{$\begin{array}{l}\text { ACE - angiotensin conversion enzyme - LVEF- left ventricle ejection frac- } \\
\text { tion; FLVDD- final left ventricle diastolic diameter on echocardiogram; } \\
\text { HR- heart rate at rest; distance, meters walked in treadmill test; SBP- systolic } \\
\text { blood pressure in mmHg; Double product, heart rate } \mathrm{x} \text { systolic blood pressure. }\end{array}$} \\
\hline
\end{tabular}

test, exercise training was programmed over the 3 months on an individual basis for each patient. It was a specific exercise-training program, seeking to establish an intensity of variable work at $60 \%$ to $80 \%$ of the peak heart rate ${ }^{12-17}$. The intensity of the exercises was controlled and monitored through a cardiac monitor, Polar model Accurox, programmed for the patient to walk at a target heart rate. Target heart rate was assessed with the Karvonem formula, where values of peak heart rate found on the treadmill test and of heart rate at rest of patients are also present, ie, target heart rate $=\%$ of work x (peak heart rate-heart rate at rest) + heart rate at rest. We tried to reach the percentage estimated at training in relation to peak heart rate assuring that it was in the ideal intensity and was not below or above the programmed intensity, assuring, therefore, greater safety. The machine set off an alerting device automatically. In addition to heart rate monitoring, the intensity of exercises was assessed with the Borg scale for rating of effort ${ }^{14,18,19}$. The exercise training method used was at intervals ${ }^{18-21}$.

Exercise training consisted of walks and localized exercises in the arms and extensions of upper and lower limbs, with their own resistance (arms, legs, and trunk) or with external resistance (dumb-bell) with performance of isotonic contractions (contraction and relaxation of skeletal muscle). These had the purpose of complementing the walking exercises, and also the stretching exercises of the great muscle groups and flexibility of the main joints (shoulder, elbow, hips, knees, and ankle) of the body ${ }^{11,18}$.

During the exercise training program and with the improvement of patients' conditioning, some programs had 


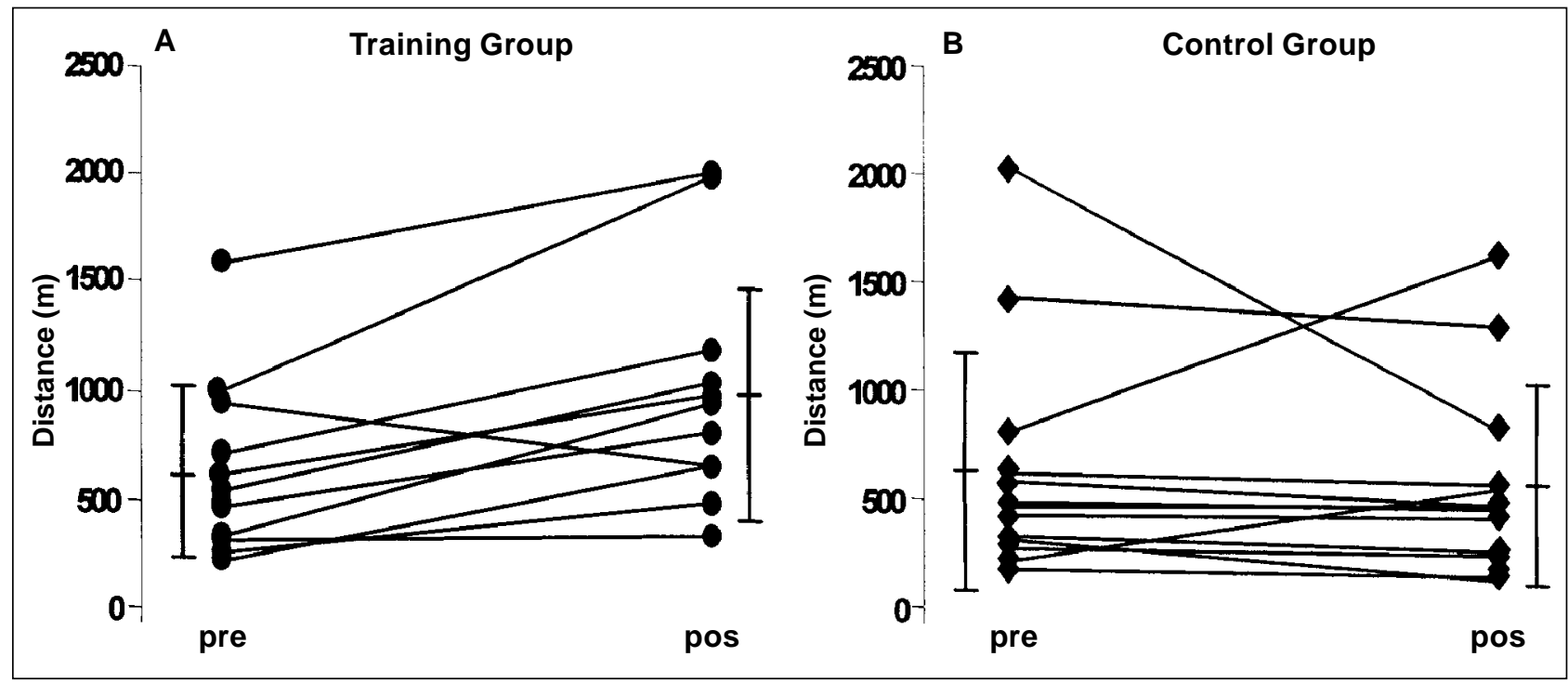

Fig. 1 - Distance walked before (Pre) and after 3 months in the exercise training group (a) and in the control group (b).

some alterations. For example, in performance, the patient increased walking speed (intensity), or increased distance walked (training volume) (1) gradually increasing exercise length up to 60 minutes and (2) increasing the percentage of workload, also gradually, up to $80 \%$ of the maximum heart rate $^{19,20}$.

Analysis of the comparison of the variation percentages between the groups was performed using the nonparametric Mann-Whitney test ${ }^{9}$.

Studies of distance walked, heart rate, and double product were performed with the multivariate analysis of mean profiles in both groups of patients with heart failure (control and exercise group). Assessments were made at 2 different times (beginning of the study and in the end of the study), and we observed the similarity regarding the mean profile of the groups, effects of the groups at the beginning and at the end, and the effects of the initial and final moment in each group ${ }^{21}$. Discussion of data obtained through statistical analysis was performed at $5 \%$ significance ${ }^{21}$.

The group comparison was performed at the beginning of the exercise training program, through the variables age, calculated using the nonparametric Mann-Whitney test, and gender, calculated using the Goodman test, for contrast of multinomial populations ${ }^{10}$.

\section{Results}

In G2 group, the distance walked at the beginning of the study and after 3 months was $624 \pm 553 \mathrm{~m}$ and $561 \pm 460 \mathrm{~m}$, respectively, with a variation of $-17 \pm 86 \%(p=n s)$. In $G 1$ group, the distance walked at the beginning of the study and after 3 months was $615 \pm 394 \mathrm{~m}$ and $970 \pm 537 \mathrm{~m}$, respectively $(\mathrm{p}<0.003$ ), with a variation of $76 \pm 71 \%$ (fig. 1 ).

Of the 12 patients in $\mathrm{G} 1,11$ increased distance walked at the end of the program in comparison with the beginning. In G2 group, only 2 patients were able to increase the distan- ce walked and the other 10 decreased the distance walked in comparison with the beginning.

In the control group, heart rate at rest in the beginning of the study and after 3 months was $82 \pm 13$ and $87 \pm 16$, respectively $(p<0.05)$, with a variation of $7 \pm 20 \%$. In G1 group, heart rate at rest in the beginning of the study and after 3 months was $82 \pm 15$ and $78 \pm 14$, respectively $(\mathrm{p}<0.05)$, with a variation of $-8 \pm-29 \%$ (fig. 2). In G2 group, heart rate at peak exercise at the beginning of the study and after 3 months was $142 \pm 23$ and $146 \pm 33$, respectively ( $\mathrm{p}=\mathrm{ns}$ ), with a variation of $3 \pm 25 \%$. In G1, heart rate at peak exercise at the beginning of the study and after 3 months was $143 \pm 24$ and $143 \pm 29$, respectively, with a variation of $-0.02 \pm 25 \%(\mathrm{p}=\mathrm{ns})$ (fig. 3).

Although variation in peak heart rate was not statistically different in G1, it decreased on average $15 \mathrm{bpm}$ after 3 months of training in 7 of the 12 patients, whereas in $\mathrm{G} 2$, it increased in 8 patients.

In G2, double product at rest at the beginning of the study and after 3 months was $9767 \pm 1452$ and $11102 \pm 3012$, respectively, with a variation of $12 \pm 24 \%(\mathrm{p}=\mathrm{ns})$. In the exercise training group, double product at rest at the beginning of the study and after 3 months was $8885 \pm 1991$ and $8269 \pm$ 1729 , respectively $(p<0.05)$, with a variation of $-8.47 \pm$ $23.50 \%$. In $\mathrm{G} 2$, double product at the beginning at peak exercise and after 3 months was $22046 \pm 6309$ and $24293 \pm$ 7373 , respectively, with a variation of $17 \pm 68 \%$. In G1, double product at peak exercise at the beginning of the study and after 3 months was $19907 \pm 7323$ and $19115 \pm 5776$, respectively, with a variation of $-19 \pm 27 \%$ (fig. 4 ).

In G2, 8 patients had a mean increase of 6295 of the double product, whereas in $\mathrm{G} 1,10$ patients had decreases in double product of 3984 .

At peak exercise in G2, distance walked/maximum exercise heart rate ratio before and after the 3 months was, respectively, $4.5 \pm 4.2$ and $3.9 \pm 3.3 \mathrm{~m} / \mathrm{b} / \mathrm{min}^{-1}(\mathrm{p}=\mathrm{ns})$ (fig. 5). At 


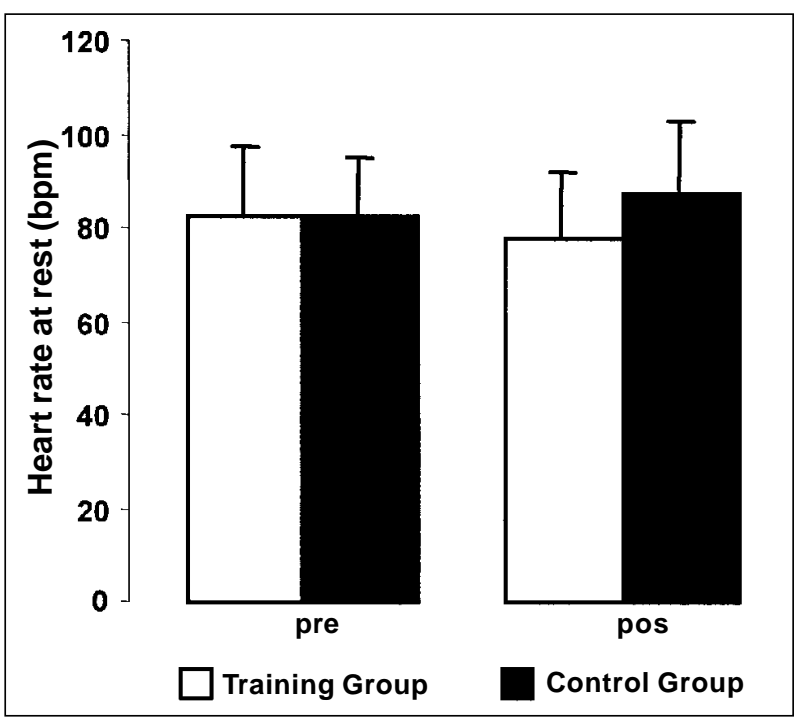

Fig. 2 - Heart rate at rest before (Pre) and after 3 months in the exercise group (a) and in the control group (b).

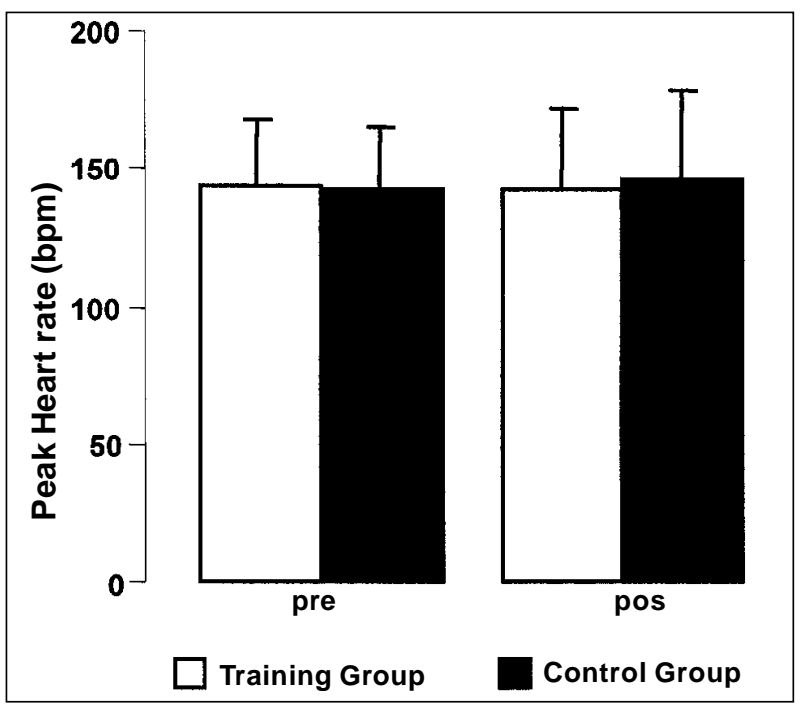

Fig. 3 - Peak exercise heart rate before (Pre) and after 3 months in the exercise training group (a) and in the control group (b).

peak exercise in $\mathrm{G} 1$, the distance walked/maximum exercise heart rate ratio before and after the training period was, respectively, $4.6 \pm 3.7$ and $7.3 \pm 4.9 \mathrm{~m} / \mathrm{b} / \mathrm{min}^{-1}(\mathrm{p}<0.0003)$.

During the study period, 5 patients from $\mathrm{G} 1$ changed NYHA Functional Class, and at the end of the exercise training program, patients were classified as the following Functional Classes: 8 were Class I, 2 were Class II and 2 were Class III. In G2, 2 patients required hospital admission and 1 patient died. In the exercise group, none of the patients required hospital admission or died.

\section{Discussion}

Our results demonstrate that a simple and easy to apply exercise program can increase distance walked during exercise, reduce double product at peak exercise, and in-

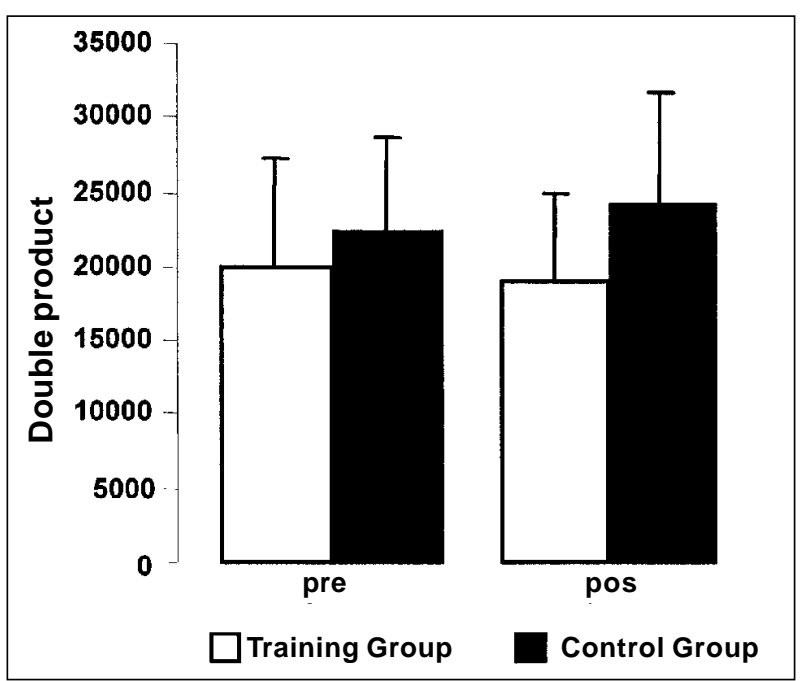

Fig. 4 - Double product at rest and exercise before (Pre) and after 3 months in the exercise group (a) and in the control group (b).

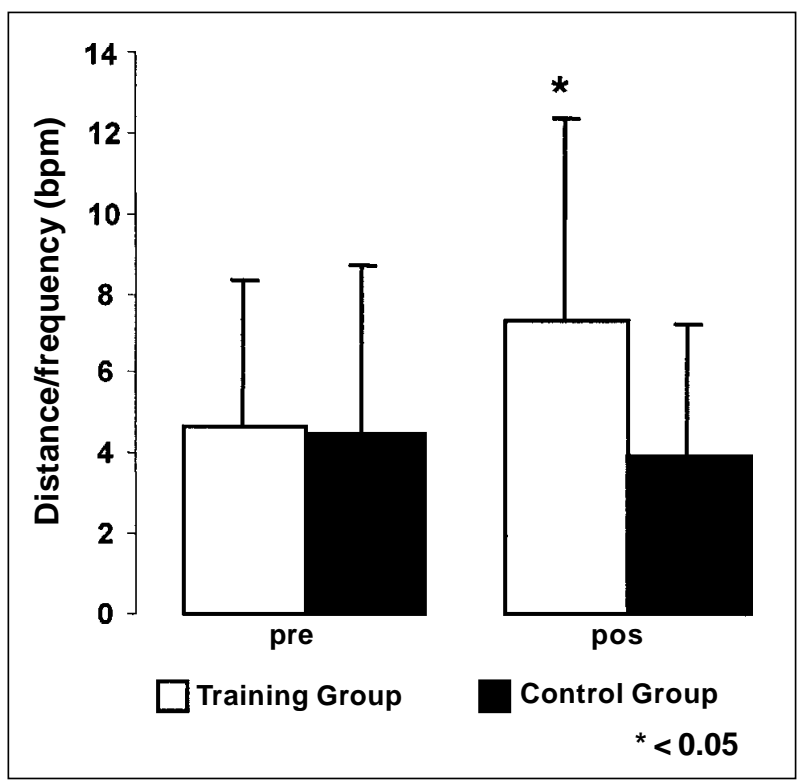

Fig. 5 - Distance walked/heart rate ratio before (Pre) and after 3 months in the exercise group and in the control group.

crease distance walked/heart rate ratio in patients with heart failure, in comparison with the control group. Treadmill assessment of exercise benefit is also possible in heart failure. Application of the program was safe, had high compliance, and the exercise group had fewer occurrences of events.

The increase in distance walked in the exercise group, together with greater effort tolerance and improvement in physical capacity, is similar to the results published by other authors, despite the small number of patients with an ischemic etiology, in our investigation ${ }^{22-25}$. Increase in exercise load was similar to that described by Wielenga et al ${ }^{25}$, Tyni-Lenné et $\mathrm{al}^{26}$, Belardinelli ${ }^{27}$, and Oliveira et $\mathrm{al}^{28}$. Our exercise-training program was also similar to that reported by Wielenga et $\mathrm{al}^{25}$, Tyni-Lenné et $\mathrm{al}^{26}$, who used aerobic 
programs with local exercises. We believe that these results are due to the increase in muscle mass, greater peripheral blood flow during exercise, metabolic alterations, including improvement in the oxidative capacity of skeletal muscles, histology and biochemical alterations, as well as improvement in ergoreflex ${ }^{28-30}$. An increase also occurred in local strength and aerobic metabolism efficacy, because these patients have fatigue and effort intolerance as limiting factors ${ }^{31,32}$. Additionally, aerobic training enhances physical capacity, peak oxygen consumption, peak voluntary ventilation, and respiratory efficacy. As previously shown, distance walked is a marker of a worse prognosis and worse clinical condition, and it is possible that an increase in distance walked is accompanied by a reduction in patients' mortality, especially those with an ischemic etiology and improvement in quality of life. The several mechanisms from which training in the ischemic group may reduce mortality include-development of collateral circulation, reduction in neuro-hormonal and anti-inflammatory activity, alteration of vascular complacence, increase in HDL-cholesterol and improvement in lipid profile, reduction of other risk factors for coronary disease, increased number of hospital visits, and greater compliance with treatment protocols ${ }^{28,33-36}$.

Our data on heart rate with exercise are similar to those published by other authors ${ }^{29,37}$. Peak heart rate in our study was similar to that described by Oliveira et a ${ }^{28}$. The explanation for the uniformity in the results of heart rate seems to be the similarity in Functional Class of patients with heart failure. In the exercise training program, heart rate is the same to that reported by Coats et al ${ }^{14}$, Sullivan et al ${ }^{36}$, and Shephard et al ${ }^{37}$, who used similar exercise training programs. As already reported, patients who took part in the aerobic exercise training tolerated a greater workload without increasing peak heart rate. The mechanism, which could explain the reduction in heart rate to the same workload, is probably the increase in vagal tonus and reduction in catecholamine levels with a reduction in sympathic tonus and baroreflex improvement, and greater R-R variability ${ }^{39,40}$.

The decrease in double product with exercise was similar to that reported by other authors ${ }^{40}$. Uniformity of results is expected, once the population was similar and the responses were chronotropic, and blood pressure was similar. However, it was different from that reported by Shephard et al ${ }^{37}$, which included changes in quality of life determined by the analysis of emotional alterations, fatigue, or dyspnea. The mechanisms by which exercise decreases double product is through a gain in physical capacity, causing a decrease in heart rate, without increasing blood pressure, probably because peripheral blood flow is increased and a tendency exists for vascular resistance to decrease during exercise, enhancing the number of capillaries and reducing fiber/ capillary ratio ${ }^{40}$.

The limitations of this study are the small number of patients, short follow-up period, and the different etiology of the patients with heart failure, even taking into account the significant results. A short follow-up period does not show if and how the beneficial effects are maintained over time; however, the simplicity of our method enables a high compliance rate with the treatment, which is probably the great limitation of these long-term protocols.

The present study shows the possibility of applying and developing with benefits a simple program of exercise training at health institutions, with possibilities of monitoring results. Exercise-training programs can promote beneficial psychological effects and a better quality of life.

In conclusion, exercise-training programs are rarely recommended in the community for patients with heart failure, due to fear of worsening of the symptoms during exercise. Our results are the first to demonstrate, in our community, through random study and a control group that exercisetraining programs can enhance physical capacity in patients with heart failure, which is shown by the increased distance walked. The reduction in heart rate could indicate a decrease in neuro-hormonal activation. It has not been determined if increased physical capacity is associated with a better prognosis; however, the small number of adverse events in the exercise group is cause for optimism. Clinical benefits, if confirmed by other studies in our community, could indicate that exercise- training programs must be routinely applied in select patients with heart failure.

\section{References}

1. Bocchi EA. Situação das indicações e resultados do tratamento cirúrgico da insuficiência cardíaca. Arq Bras Cardiol 1994; 63: 523-30.

2. II Diretrizes da Sociedade Brasileira de Cardiologia para o Diagnóstico e Tratamento a Insuficiência Cardíaca. Arq Bras Cardiol 1999; 72 (supl. I).

3. BocchiEA,BacalF,BellottiG,CarraraD, RamiresJAF.Efeitosdocarvedilol(Bloqueador b1b2a1)na insuficiência cardíaca refratária. Arq Bras Cardiol 1998; 71: 169-73.

4. Jennings GL, Esler MD. Cirulatory regulation at rest and exercise and the functional assessment of patients with congestive heart failure. Circulation 1990; 81: 5-13.

5. Braith RW, Mills RM Júniors. Exercise training in patients with congestive heart failure, how to achieve benefits safely, Postgraduate Med 1994; 96: 119-30.

6. Arakaki H, Magalhães HM. Programas supervisionados em reabilitação cardiovascular - abordagem de prescrição de exercício. Rev SOCESP 1996; 6: 23-30.

7. Bolfarine H, Bussab WO. Elemento de Amostragem, SINAPE, 11, 1994. Anais, 161.

8. Naughton J, Balke B, Nagle F. Refinements in method of evaluation and physical conditioning before and after myocardial infarction. Am J Cardiol 1964; 14: 837-43.
9. Siegel S, Castellan Jr. NJ. Non Parametric Statistics for the Behavioral Sciences. $2^{\text {nd }}$ ed. New York: McGraw-Hill, 1988: 321.

10. Neto TLB. Fisiologia do exercício aplicada ao sistema cardiovascular. Rev SOCESP 1996; 6: 6-10.

11. Oliveira JF, Salvetti X. Programas não supervisionados em reabilitação cardiovascular-abordagem da prescrição de exercício. Rev SOCESP 1996; 6:31-9.

12. Buchler RDD, Ferraz AS, Menghelo RS. Princípios gerais e aplicações de reabilitação. Rev SOCESP 1996; 6: 11-22.

13. Pollock ML, Wilmore JH, Foxii SM. Exercícios na Saúde e na Doença; Avaliação e Prescrição para Prevenção e Reabilitação, $1^{\text {a }}$ ed. Rio de Janeiro: Medsi, 1986.

14. Coats AJS, Adamopoulos S, Meyer TE, et al. Controlled trial of physical training in chronic heart failure. Circulation 1992; 85: 2119-31.

15. Wilmore JH, Costill DL. Physiology of sport and exercise. Human Kinetcs 1994; $1: 176$.

16. Guimaraes GV,BellottiG, Wajngarten M, TeixeiraL, RamiresJF, BocchiEA.Exercise 
and heart failure. Relation of the severity of the disease to the anaerobic threshold and the respiratory compensation point. Arq Bras Cardiol 1999; 73: 339-8.

17. American College Sports Medicine-Principles of exercise prescription. In:Guidelines of Exercise Testing and Prescription. $4^{\mathrm{a}}$ Ed. New York: Lea \& Febiger, 1991.

18. Yazbek PJ, Battistella LR. Condicionamento físico do atleta ao transplantado; aspectos multiciplinares na prevenção e reabilitação cardíaca, $1^{\mathrm{a}}$ ed. São Paulo: Savier e Associação Paulista de Medicina, 1994

19. Magnusson $\mathrm{G}$. Comparison of isotonic and isometric training in patients with chronic heart failure. In: World Congress on Heart Failure - Mechanism and Management. Proceedings, 1998.

20. Morrison DF. Multivariate Statical Methods. New York: McGraw-Hill, 1976.

21. The Solvd Investigators. Effect of enalapril on survival in patients with reduced left ventricular ejection fractions and congestive heart failure. N Engl J Med 1991; 325: 293-302

22. Oliveira MTJ, Guimarães GV, Barreto ACP. Teste de $6 \mathrm{~min}$ em insuficiência cardíaca. Arq Bras Cardiol 1996; 67: 373-4.

23. Silva CES, Seixas MA, Moreira MM, Ortiz J. Insuficiência cardíaca congestiva Novos métodos de avaliação da função ventricular. Rev SOCESP 1999; 9: 818.

24. Beltner V, Weiner OH, Yussuf S, et al. Prediction of mortality and... patients with left ventricular dusfunction. JAMA 1993; 270: 1702-7.

25. Wielenga RP, Coats AJS, Mosterd WL, et al. The role of exercise training in chronic heart failure. Heart Review 1997; 78: 431-6.

26. Tyni-Lenné R, Gordon A, Jansson E, et al. Skeletal muscle endurance training improves peripheral oxidative capacity, exercise tolerance, and health - related quality of life in women with chronic congestive heart failure secundary to either ischemic cardiomyopathy or idiopathic dilated cardiomyopathy. Am J Cardiol 1997; 80: 1025-9.

27. Belardinelli R. Moderate Physical activity should be prescribed along with appropriate drug therapy for patients with congestive heart failure who are stable. Circulation 1999; 99: 1173-82.

28. Oliveira JF, Salvetti X, Almeida D, Salles A, et al. Freqüência cardíaca no limiar anaeróbio em insuficiência cardíaca. IV congresso brasileira de ergometria e reabilitação cardiovascular. Arq Bras Cardiol 1998; 70: 137.
29. Yamani MH, Wells L, Massie BM. Relation of the nine-minute self-powered treadmill test to maximal exercise capacity and skeletal muscle function in patients with congestive heart failure. Am J Cardiol 1995; 76: 788-92.

30. Hambrecht R, Fiehn E, Adams V, et al. Effects of exercise training on muscle alterations in patients with chronic heart failure. In: World Congress on Heart Failure - Mechanism And Management. Proceedings, 1998.

31. I Consenso Nacional de Reabilitação Cardiovascular, na fase crônica da evolução clínica. Arq Bras Cardiol 1997; 69: 267-91.

32. Cohn JN. Prevention of heart failure. Cardology 1999; 92(suppl 1): 22-5.

33. Bol E, Vries WR, Mosterd WL, Wielenga RP, Coats AJ. Cardiopulmonary exercise parameters in relation to all-sause mortality in patients with chronic heart failure. J Cardiol 2000; 72: 255-63.

34. Wright DJ, Tan LB. The role of exercise testeting in the evaluation and management of heart failure. Postgrad Med J 1999; 75 (886): 453-8.

35. Kiilavuori K, Toivonen L, Näveri H, et al. Reversão das alterações autonômicas pelo treinamento físico por avaliação através da variabilidade da freqüência cardíaca na insuficiência cardíaca crônica. Eur Heart J 1995; 16: 490-5.

36. Sullivan MJ, Higginbotham, MB, Cobb FR. Increase exercise ventilation in patients with chronic heart failure: intact ventilatory control despite hemodynamic and pulmonary abnomalities. Circulation 1988; 77: 552-9.

37. Shephard RJ, Kavanagh T, Mertens DJ. On the prediction of physiological and psychological responses to aerobic training in patients with stable congestive heart failure, J Cardiopul Rehabil 1998; 18: 45-51.

38. Sellier P. Overview of the results of exercise training studies in heart failure. In: World Congress on Heart Failure - Mechanism and Management. Proceedings 1998.

39. Yazbek PJ, Santomauro AC, Silva PRS, et al. Resposta cronotrópica e pressórica nas miocardites em portadores de insuficiência cardíaca durante prova ergométrica. correlação das variáveis espirométrica ao esforço. Arq Bras Cardiol 1993; 60: 405-10.

40. Negrão CE, Barreto ACP. Effect of exercise training on chronic heart failure: autonomic, hemodynamic and metabolic implications. Rev SOCESP 1998; 8: 694 